\title{
Not All College Is Equal When It Comes to Wealth and Race
}

Su Jin Jez

\section{INTRODUCTION AND CONTEXT}

I was invited to respond to the article presented by William R. Emmons and Lowell R. Ricketts, "College Is Not Enough: Higher Education Does Not Eliminate Racial and Ethnic Wealth Gaps,"1 and received a pre-conference version of the article to prepare my remarks. The authors analyzed the role of higher education in explaining racial and ethnic disparities in wealth. As the title makes clear, Emmons and Ricketts found that disparities in postsecondary education do not completely explain racial and ethnic disparities in wealth. More notably, Emmons and Ricketts found that racial and ethnic differences in family structure, luck, income windfalls, and inheritances explained even less of wealth disparities than higher education, while racial and ethnic differences in "financial decisionmaking" 2 were more important than all the above factors.

My thoughts on their article at that time are presented here. I begin with commentary focused on their methods and end by proposing theories for their more puzzling findings.

\section{EMMONS AND RICKETTS PUSH ECONOMISTS TO THINK DIFFERENTLY ABOUT STRATIFICATION}

The findings of Emmons and Ricketts (2016) contribute to our understanding of wealth disparities in the United States, but its innovative contribution is the way it approaches how we think about racial disparities in wealth. Quantitative research methods can lead to the oversimplification of issues of race. Due to statistical methods, race becomes and remains a variable that tends to encapsulate everything we cannot measure. Instead of trying to understand what race is and is not, quantitative researchers tend to focus on the fit of their statistical modeling. Acknowledging that practice, Emmons and Ricketts challenge the postracial model with the structural factors model. The postracial model assumes that the wealth returns to education are equal and that all individuals face the same opportunities and choices. The structural

Su Jin Jez is an associate professor of public policy and administration at California State University, Sacramento. She is also a faculty associate with the Education Insights Center (EdInsights). This article was prepared for remarks delivered at the symposium, "Does College Level the Playing Field? Racial and Ethnic Differences in Family Wealth Among College-Educated Families," sponsored by the Center for Household Financial Stability and the Research Division of the Federal Reserve Bank of St. Louis, May 25-26, 2016.

Federal Reserve Bank of St. Louis Review, First Quarter 2017, 99(1), pp. 45-51. http://dx.doi.org/10.20955/r.2017.45-51

(c) 2017, Federal Reserve Bank of St. Louis. The views expressed in this article are those of the author(s) and do not necessarily reflect the views of the Federal Reserve System, the Board of Governors, or the regional Federal Reserve Banks. Articles may be reprinted, reproduced, published, distributed, displayed, and transmitted in their entirety if copyright notice, author name(s), and full citation are included. Abstracts, synopses, and other derivative works may be made only with prior written permission of the Federal Reserve Bank of St. Louis. 
factors model relaxes this assumption, allowing for different wealth returns to education and uses variance from racial and ethnic group means rather than one construct across all groups.

This nontrivial shift in thinking acknowledges structural disadvantages that groups facing discrimination struggle against- this thinking has largely been absent in quantitative research, left largely to qualitative scholars of race. Emmons and Ricketts analyze the data using both models and clearly compare the results. While race scholars may still be dissatisfied with the structural factors model, it is a huge step for economic research. The recognition that there are structural, complex factors that underlie wealth accumulation and the attempt to measure it are laudable in and of themselves.

\section{THOUGHTS ON METHODS: VARIABLE LABELS AND THE NONLINEARITY OF WEALTH}

At the May conference, it was noted how media outlets had run with a spin of the Emmons and Ricketts findings that was not wholly accurate. As such, the authors were striving to be careful about how they presented their research to minimize misunderstandings. My next few comments focus on how some of the key variable labels used in this article can lead to unintended interpretations of their findings. In addition, I also note some methodological changes that can help to address these misinterpretations and suggest an alternative specification of wealth.

\section{IS FINANCIAL DECISIONMAKING REALLY JUST ANOTHER WAY TO MEASURE WEALTH?}

Emmons and Ricketts made an effective case to change the way we model and think about race and wealth. However, caution must be used in how findings are described, even with a revised analytical model. In the article I reviewed, Emmons and Ricketts used the term "financial decisionmaking" to describe where people held their wealth-in savings, in investments, etc. While the authors acknowledged that these may not be active choices, they continued to use the terms decisionmaking and choice. This language puts the onus on the individual as if each person has the same ability to allocate wealth, but this is not true. The ability to allocate wealth (or make financial decisions, in the language of the article) is largely determined by how much wealth an individual has. For example, a low-wealth individual will stretch to buy a house but will not have extra funds to allocate to financial assets or to hold in the bank. The construction of the financial decisionmaking variable by Emmons and Ricketts made it look like this lower-wealth individual actively chose not to allocate wealth to financial assets or cash, but rather the individual had no extra wealth to allocate after purchasing a home. One could argue that this lower-wealth individual could buy a less-expensive house and then put the extra funds into the stock market. This is true, but for higher-wealth individuals, they could buy the house they want without concern about the cost, plus have extra to invest in stocks, bonds, a business, or hold as cash—all without doing any real financial decisionmaking. In fact, this excess wealth has to be put somewhere, which, using the language 
of the article, made it look like the higher-wealth individual was making active financial decisions when the individual was simply holding onto his or her wealth. These were not choices that reflect financial preferences-I argue they were a reflection of wealth itself.

Moreover, wealth of one type often builds wealth of another type, making it seem as if higher-wealth individuals were actively diversifying when they were not. For example, a business investment may yield cash savings (in the form of income payments) or a financial asset may pay dividends that yield cash savings. As such, stating that racial and ethnic differences in financial decisionmaking were a key determinant of differences in racial and ethnic wealth is misleading and circular. Emmons and Ricketts could address this by renaming the variable (to help address the misleading aspect of it) and then measuring how individuals allocate investments or more disposable resources, while accounting for the fact that lower-wealth individuals will spend a greater proportion of their financial assets on their homes. Otherwise, this variable seems to largely just measure wealth.

\section{WHEN IS LUCK NOT LUCK?}

Emmons and Ricketts also examined whether racial and ethnic differences in luck explain racial and ethnic differences in wealth. They defined "luck" as health, income windfalls or shortfalls, and inheritances. It is not clear whether down payment assistance would be included as an income windfall; however, significant numbers of homeowners depend on assistance from family members to purchase a home. However, even if such assistance was queried in the survey, most individuals do not consider down payment assistance from family members as gifts or income. Moreover, loans provided from family members were not accounted forthese loans may never be paid back or be paid back without interest-and perhaps be paid back only to be inherited later. This means that the role of down payment gifts and loans was likely not adequately accounted for with these data. Such assistance is critical to understanding racial and ethnic disparities in wealth as it is a driver of the cycle of wealth that is racially and ethnically motivated.

This access to financial resources can assist in providing the cushion that helps an individual build wealth (as most Americans do in their homes) and weather a storm like the Great Recession of 2007-09. This access to financial resources from family members is more likely among Whites because they have more wealth, particularly in the form of equity in their homes that they can borrow against since they have homes that have appreciated more. This resource likely had an insulating impact during the recession. Not only do Whites have greater access to down payment assistance, they are then more able to access lower-cost mortgages and purchase homes in areas that will appreciate more quickly. Altogether, this exacerbates racial and ethnic disparities in wealth and would not be accounted for in this article's analysis.

\section{PERHAPS THE IMPACT ON WEALTH IS NOT LINEAR}

In my own research on wealth (with wealth as a predictor of higher education), I have found that wealth's impact was not linear or any linear transformation (Jez, 2008, 2014). This 
leads me to wonder if there could be a similar relationship in this analysis, which reverses the directionality (higher education as a predictor of wealth). As such, I recommend that Emmons and Ricketts consider an ordinal classification for wealth and then perform an ordered logistic regression. It may be that there are changes in wealth that do not conform to smooth functions.

\section{THOUGHTS ON PIECING TOGETHER PUZZLING FINDINGS}

Emmons and Ricketts presented two puzzling findings, and I propose explanations to make sense of them. First, I delve into why more-educated Blacks and Hispanics lost more wealth as a percentage from 2007 to 2013 than their less-educated counterparts. Then, I discuss the authors' findings on why racial and ethnic gaps persist even among college-educated individuals.

\section{WHY DOES COLLEGE APPEAR TO BE HARMFUL FOR THE ASSET ACCUMULATION OF BLACKS AND HISPANICS?}

Emmons and Ricketts also analyzed changes in wealth over time by race, and their findings underscore how having some wealth can be instrumental in building wealth (Figure 1). The time period they examined covered the Great Recession of 2008 and the economic recovery. They found that a four-year college degree insulated Whites and Asians from more substantial losses in wealth during the Great Recession. However, the opposite was true for Blacks and Hispanics: Blacks and Hispanics with four-year degrees had greater losses in wealth during the Great Recession and its recovery than Blacks and Hispanics without four-year degrees.

The fact that Whites and Asians generally fared much better over this time period was not surprising. During a recession, having some financial resources could be the cushion that allows an individual to survive until the economy recovers. It allows you to be able to wait for an appropriate job after losing your job. It allows you to not have to take out high-cost loans, such as from a payday lender, or use credit cards to cover ongoing costs when you have no means to pay off that debt each month. It even allows you to be able to take a job interview because you can afford child care during the interview. It allows you to sustain the networks that will get you the next job-the networks that exist based on some event that has costs, such as meeting for coffee or a round of golf. Or, even if networking is free, it still requires child care. The fact that more-educated Whites and Asians fared better than most was likely a reflection of their financial resources prior to the Great Recession.

However, the finding that educated Blacks and Hispanics ended up so much worse off than their less-educated counterparts was puzzling on its face. My first thought went immediately to the impact that many Americans felt during this recession-the devaluation of homes. And the issue of home wealth is a major one when trying to understand disparities in wealth by race and ethnicity. On this aspect of racial and ethnic disparities in wealth, we have two well-documented facts:

(i) Most Americans hold most of their wealth in their homes (home equity).

(ii) The decision of who gets to purchase expensive houses that appreciate quickly is based on race. 


\section{Figure 1}

\section{Change in Median Net Worth between 2007 and 2013 by Race and Education}

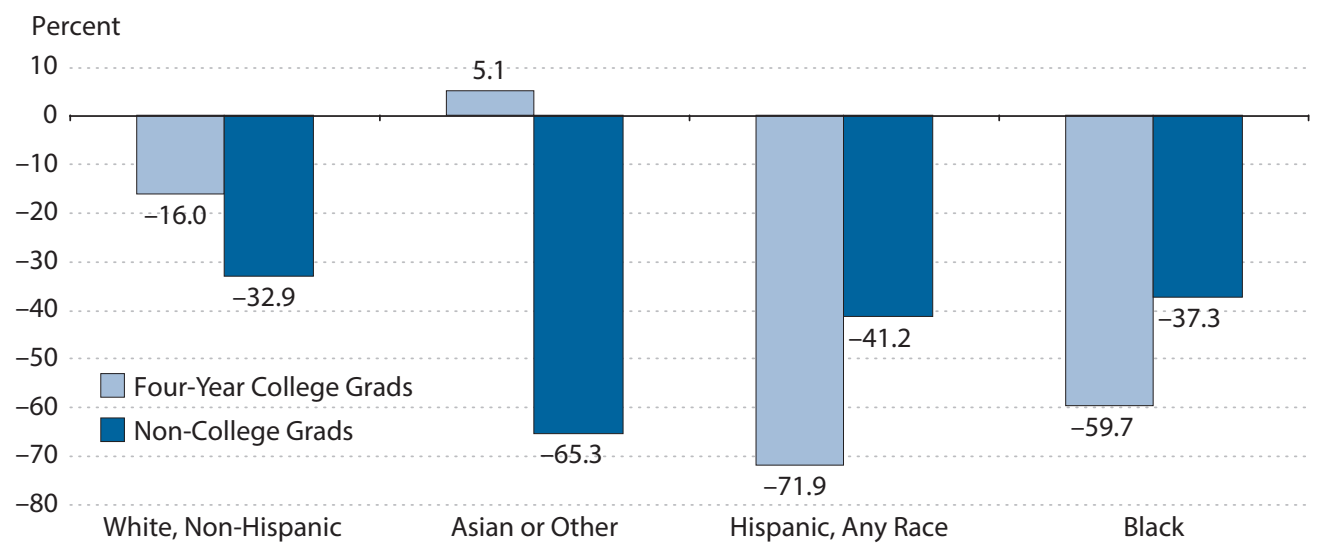

SOURCE: Survey of Consumer Finances, as used in Emmons and Ricketts (2016).

The first fact is well supported and straightforward. The second fact merits further discussion. Explicit racism in housing exists in the denial of mortgages to Blacks and redlining that was common and legal for a very long time - and that continues today despite the illegality of such practices. Implicit racism in housing exists in that sellers select buyers (and buyers' agents guide buyers), which leads to Whites selling valuable property to Whites despite changes in explicit housing policies. Moreover, zoning policies with disparate impact (for example, running rail systems above ground in lower-wealth neighborhoods but running them below ground in higher-wealth neighborhoods) and minorities facing higher-cost mortgages even with the same credit profile further perpetuate racial gaps in home wealth. These racist policies and practices have meant that Whites are more likely to own houses and own houses in areas that appreciate more quickly.

How does this explain the Emmons and Ricketts finding displayed in Figure 1? First, Blacks and Hispanics may have purchased homes in areas that faced less demand and were much slower to recover from the housing crisis-likely due to racist housing policies as explained previously and to simply having less wealth initially. But why would more-educated Blacks and Hispanics be hit harder? Simply because they were more able to own homes in the first place-they placed huge sums of wealth into their homes (like most Americans of any racial or ethnic group). And then they not only lost it all but also ended up in debt when their homes were worth less than the amount owed on their mortgage. Less-educated Blacks and Hispanics were less likely to have been able to buy a house in the first place, so they did not have as much wealth to lose as their more-educated counterparts. The wealth positions of less-educated Asians closely resemble those of educated Blacks and Hispanics. Less-educated Asians likely also bought homes in areas that are slow to appreciate and quick to depreciate, purchased more recently, and, as a result, were caught in the housing bubble that preceded the Great Recession. This is likely due to the heterogeneity in the Asian racial categorization, which 
creates a single identity for Chinese and Japanese Americans who have higher levels of education and have amassed greater wealth and the less-educated and lower-wealth Hmong and Filipino Americans.

\section{WHY DOES EDUCATION NOT SEEM TO MATTER FOR ASSET ACCUMULATION?}

For the analysis that drove the title of their article, Emmons and Ricketts analyzed changes in wealth for just those with a baccalaureate degree and found that racial and ethnic disparities in wealth persist even among the college educated. They also mentioned in their conclusion that they performed a similar analysis for just those with professional and graduate degrees with the same results. Why might this be happening? First, while the research is mixed on whether or not it matters what college you attend, it is fairly consistent that which college you attend does matter for minorities. Sadly, the types of colleges that provide the greatest returns for minorities-namely, highly selective ones-are the colleges with the smallest representation of minority students. Emmons and Ricketts treated all bachelor's degrees the same; however, which college awarded that degree makes a difference for minorities. If Emmons and Ricketts have data on which colleges these individuals attended, it would be interesting to see if that matters.

Also related is the fact that minorities are more likely to receive degrees in lower-paying fields, such as education. If possible, it would be informative to control for degree field in addition to level (and institution). Generally, not all degrees are created equal, and these disparities are pronounced for minorities and correlate with the racial and ethnic gaps found in wealth accumulation.

\section{INNOVATIVE FRAMING HOPEFULLY WILL SHIFT CONVERSATIONS ABOUT WEALTH}

This article's framing and more theoretical underpinnings that considered structural factors that impact asset accumulation were innovative, laudable, and exciting. I hope this work by Emmons and Ricketts drives more work that moves beyond traditional economic models. I applaud the authors for thinking about how their research will be understood and conveyed. The research conference motivated by this article not only allowed for a rich discussion of this article, but also a rich discussion of related issues. These discussions continued between sessions and after attendees departed the St. Louis Fed. I look forward to future contributions by Emmons and Ricketts and seeing the prominent role the Federal Reserve Bank of St. Louis plays in promoting these conversations to the forefront. 


\section{NOTES}

1 See Emmons, William R. and Ricketts, Lowell R. "College Is Not Enough: Higher Education Does Not Eliminate Racial and Ethnic Wealth Gaps." Federal Reserve Bank of St. Louis Review, First Quarter 2017, 99(1), pp. 7-39.

2 The term "financial decisionmaking" throughout this article is used by Emmons and Ricketts in their article and is used in their sense. In my opinion, the term is a misnomer.

\section{REFERENCES}

Jez, Su Jin. "The Influence of Wealth and Race in Four-Year College Attendance." Center for Studies in Higher Education Research \& Occasional Paper Series 18-08, University of California, Berkeley, November 2008; http://www.cshe.berkeley.edu/sites/default/files/shared/publications/docs/ROPS-Jez-Wealth-Race-11-13.pdf.

Jez, Su Jin. "The Differential Impact of Wealth Versus Income in the College-Going Process." Research in Higher Education, November 2014, 55(7), pp. 710-34; https://doi.org/10.1007/s11162-014-9332-0. 
